\title{
Broadband Printed Cross-Dipole Element with Four Polarization Reconfigurations for Mobile Base Station Array Antenna Applications
}

\author{
Soon-Young Eom, ${ }^{1}$ Ic-Pyo Hong, ${ }^{2}$ and Jong-Myeon Kim ${ }^{1}$ \\ ${ }^{1}$ Radio Technology Research Department, Electronics and Telecommunications Research Institute, Daejeon 305-700, Republic of Korea \\ ${ }^{2}$ Division of Information \& Communication Engineering, Kongju National University, Cheonan 330-717, Republic of Korea
}

Correspondence should be addressed to Ic-Pyo Hong, iphong@kongju.ac.kr

Received 18 February 2011; Accepted 26 April 2011

Academic Editor: Zhongxiang Q. Shen

Copyright ( $\odot 2011$ Soon-Young Eom et al. This is an open access article distributed under the Creative Commons Attribution License, which permits unrestricted use, distribution, and reproduction in any medium, provided the original work is properly cited.

This paper describes a broadband printed cross-dipole element with four polarization reconfigurations (BPCDE_PR). The BPCDE_PR can configure two linear and two circular polarizations in the operating band of $1.7-2.5 \mathrm{GHz}$. To implement the broadband polarization reconfigurations, switched network type broadband phase shifters are proposed and designed. The fabricated BPCDE_PR prototype with switched network including broadband phase shifters shows good electrical performances and the desired polarization reconfigurable functions in the operating band.

\section{Introduction}

In wireless mobile communication systems, base stations or repeater antennas are essential for their role in making a wireless signal path connection with wireless terminals. In conventional technology, they are usually designed for single-mode operation that radiates mainly linear polarization. However, in the future, various wireless services will gradually converge to the use of a single wireless multimode terminal that can give multimode functions operating according to a selected service or frequency band. Fading will be dependent upon wireless service bands and surrounding environments and will cause a distortion or change of excited polarization. A switchable property in polarization or frequency can allow the user to access any existing network. In this regard, it is desirable that base stations or repeater antennas also provide multimode functions to reconfigure polarization and/or frequency.

Numerous researchers have recently investigated polarization or frequency reconfigurable antennas [1-6] but most of the results showed narrow bandwidth characteristics. Practically, it is difficult to use such antenna schemes due to complicated switching circuits. In this paper, a new broad- band printed cross-dipole (CDP) element with four polarization reconfigurations (BPCDE_PR) is proposed to improve the operating bandwidth. It is designed in the operating band of $1.7-2.5 \mathrm{GHz}$ (about $40 \%$ in fractional bandwidth). The broadband feed network proposed in this paper to control polarization shows good electrical performances of over $50 \%$. The BPCDE_PR proposed in this paper can control linear $\left(+45^{\circ} /-45^{\circ}\right)$ polarizations or circular polarizations (LHCP/RHCP) in the operating band for PCS, WCDMA, WiBro, and WLAN (WiFi) services in South Korea. The proposed antenna can also be used as an array element in broadband base stations or repeater antennas, or broadband terminal antennas because of its broadband characteristics and polarization reconfigurability.

\section{BPCDA_PR Design}

The internal block diagram of the BPCDE_PR proposed in this paper is shown in Figure 1. A broadband printed crossdipole element is put on the top side of the BPCDE_PR, and a broadband feed network that can generate and control four different polarizations is attached on its bottom side. 


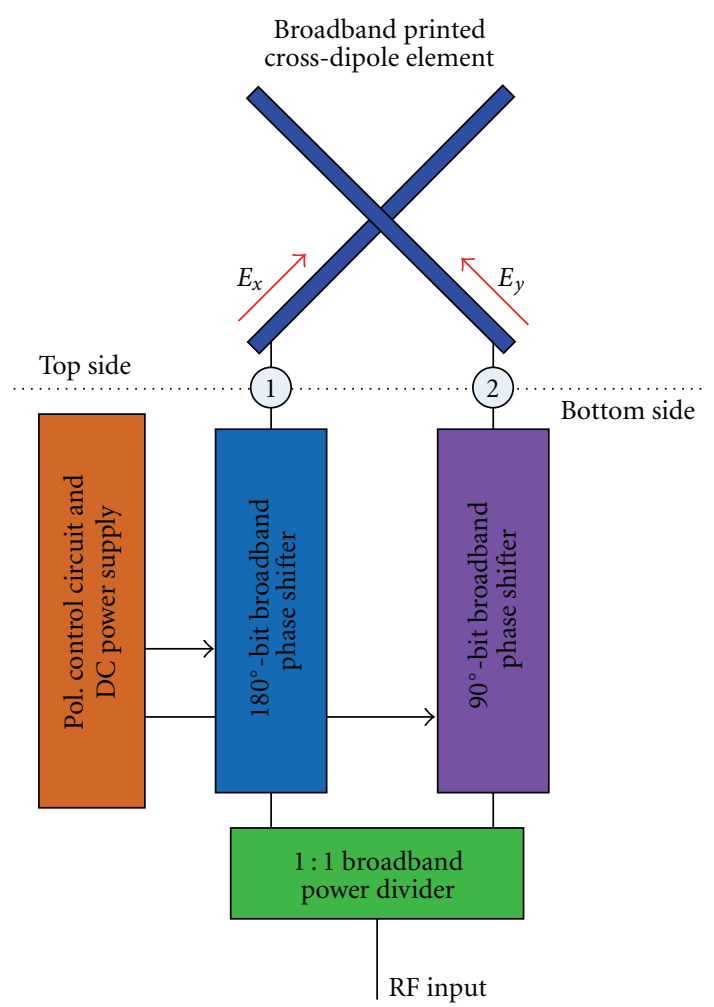

FIGURE 1: Internal block diagram of BPCDE_PR.

TABLE 1: Control paths for polarization reconfigurations.

\begin{tabular}{lccccc}
\hline Polarization & $\begin{array}{c}\text { Relative } \\
\text { phase } \\
\text { differences }\end{array}$ & Path 1 & Path 2 & Path 3 & Path 4 \\
\hline$+45^{\circ}$ linear & $0^{\circ}$ & OFF & ON & ON & OFF \\
$-45^{\circ}$ linear & $180^{\circ}$ & ON & OFF & ON & OFF \\
LHCP & $90^{\circ}$ & ON & OFF & OFF & ON \\
RHCP & $-90^{\circ}$ & OFF & ON & OFF & ON \\
\hline
\end{tabular}

In order to implement the broadband polarization antenna element proposed in this paper, a broadband antenna element and a broadband feed network for polarization reconfiguration (BFN_PR) are required as shown in Figure 1. The antenna element is composed of two linear antennas that form an orthogonal structure and radiates two orthogonal linear components, $E_{x}$ and $E_{y}$, into free space. Its two inputs are physically connected with two outputs of a feed network. To make the properly linear or circular polarizations mentioned above, two output signals from the feed network should be precisely controlled over the desired broadband [7].

2.1. Broadband Antenna Element. The broadband antenna element is composed of two printed dipole elements, and each printed dipole element is orthogonally crossed on the base ground plate. Each printed dipole element with a balun circuit is shown in Figure 2, and the incident wave directly
TABLE 2: Gain and axial ratio performances of BPCDE_PR.

\begin{tabular}{cccc}
\hline Frequency & Polarization & Gain $(\mathrm{dBi})$ & $\begin{array}{c}\text { Max. axial ratio }(\mathrm{dB}) \text { at } \\
3 \mathrm{~dB} \text { beamwidth }\end{array}$ \\
\hline \multirow{3}{*}{$1.7 \mathrm{GHz}$} & $+45^{\circ}$ linear & 7.19 & -20.75 \\
& $-45^{\circ}$ linear & 7.19 & -24.54 \\
& LHCP & 6.80 & 1.58 \\
& RHCP & 6.66 & 1.61 \\
\hline \multirow{3}{*}{$2.1 \mathrm{GHz}$} & $+45^{\circ}$ linear & 7.17 & -19.97 \\
& $-45^{\circ}$ linear & 7.07 & -17.02 \\
& LHCP & 7.47 & 1.96 \\
$2.5 \mathrm{GHz}$ & RHCP & 7.05 & 2.23 \\
\hline \multirow{3}{*}{} & $+45^{\circ}$ linear & 7.55 & -17.89 \\
& $-45^{\circ}$ linear & 7.38 & -19.30 \\
& LHCP & 7.05 & 2.08 \\
& RHCP & 6.69 & 2.07 \\
\hline
\end{tabular}

radiates in free space. The balun circuit in this element is used for transforming an unbalanced signal to a balanced signal and input impedance matching [8]. Although the I/O impedance transformation ratio of the integrated balun structure is not large, it can give a simple implementation and allows the designer to choose various optimal design parameters.

The printed dipole element is realized on a RF35 board from the Taconic company with a dielectric permittivity of 3.5 and a thickness of $0.762 \mathrm{~mm}$, and a conductor thickness 

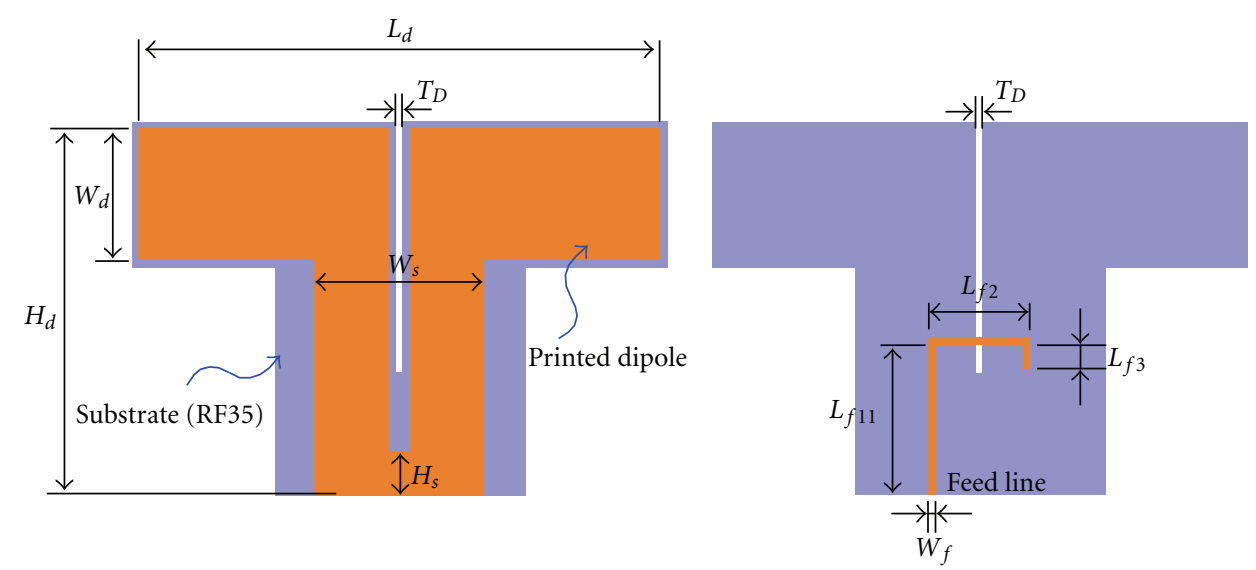

(a) Front and back-view of dipole 1
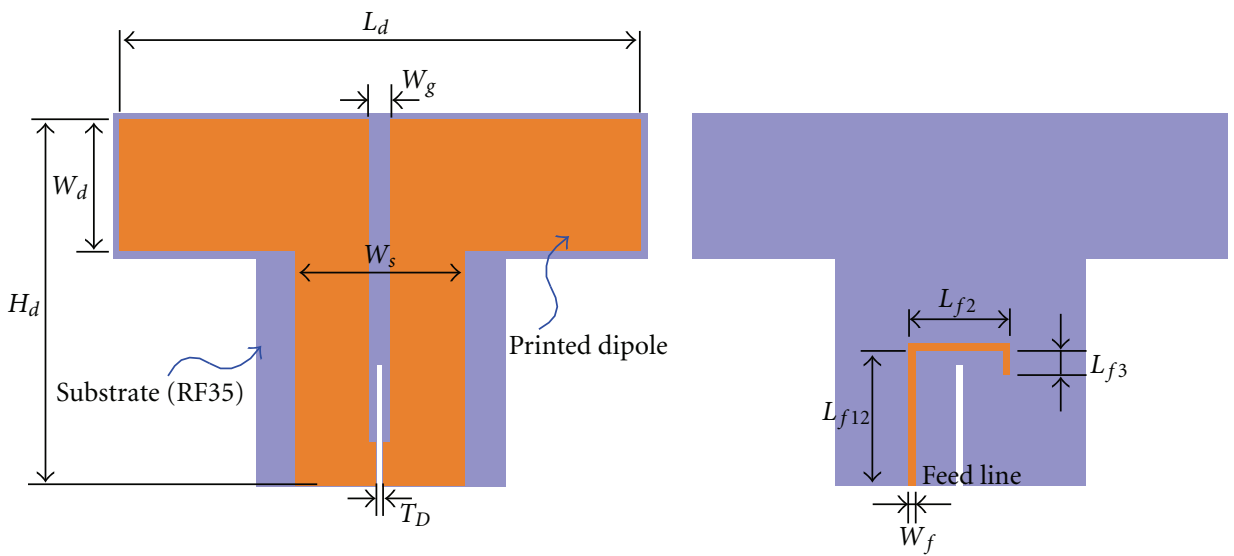

(b) Front and back view of dipole 2

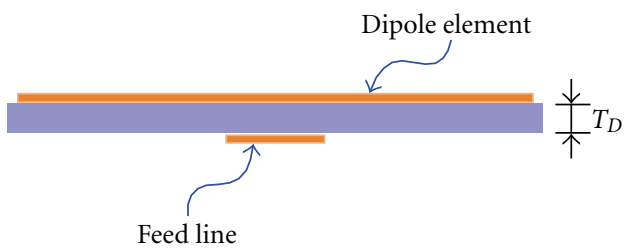

(c) Top view

Figure 2: Design parameters of each printed dipole element $\left(T_{D}=0.76 \mathrm{~mm}, W_{d}=17.50 \mathrm{~mm}, L_{d}=84.00 \mathrm{~mm}, H_{d}=49.50 \mathrm{~mm}, W_{g}=\right.$ $\left.3.00 \mathrm{~mm}, W_{s}=26.00 \mathrm{~mm}, H_{s}=6.00 \mathrm{~mm}, W_{f}=1.00 \mathrm{~mm}, L_{f 11}=22.30 \mathrm{~mm}, L_{f 12}=20.30 \mathrm{~mm}, L_{f 2}=15.50 \mathrm{~mm}, L_{f 3}=5.00 \mathrm{~mm}\right)$.

of $0.035 \mathrm{~mm}$. The design parameters of the printed dipole element were optimized using CST Microwave Studio (Ver. 5.1). The final design parameters are summarized in Figure 2. The input feed line $L_{f 1}$ has two different values $\left(L_{f 11}\right.$ and $L_{f 12}$ ) with an offset of $\pm 1 \mathrm{~mm}$ in order not to overlap in an orthogonal cross-section as shown in Figures 2(a) and 2(b).

Antenna gain and radiation patterns can be changed significantly by placing the cross-dipole element into a cavity enclosure and changing the geometry of the enclosure. It is found that the presence of cavity enclosure limits the amount of radiation to the sides and back. Also, the cavity can provide the positive effect on antenna gain and radiation pattern [9]. Therefore, a metallic cavity ring structure is introduced in order to provide stable radiation patterns with a high gain characteristic over the operating band. The printed cross-dipole element is put at the center of the cavity ring with a diameter of $140 \mathrm{~mm}\left(\cong 0.98 \lambda_{o}\right)$, a height of $49.5 \mathrm{~mm}$ $\left(\cong 0.35 \lambda_{o}\right)$, and a thickness of $1 \mathrm{~mm}$.

Figure 3 shows the measured electrical performances of a printed cross-dipole element with and without the cavity ring over the operating band. As shown in Figure 3(a), the measured port return loss is less than $-11.5 \mathrm{~dB}$ without the cavity ring and $-9.3 \mathrm{~dB}$ with it. The isolation between the two ports shows more than $35 \mathrm{~dB}$ without the cavity ring and $32 \mathrm{~dB}$ with it. The radiation patterns of the printed cross-dipole element without the cavity ring, which are measured at $1.7 \mathrm{GHz}, 2.1 \mathrm{GHz}$, and $2.5 \mathrm{GHz}$, show antenna gains at boresight of $9.1 \mathrm{dBi}, 7.3 \mathrm{dBi}, 5.8 \mathrm{dBi}$, respectively, shown in Figures 3(b)-3(d). A pit at 0 degree of the $\mathrm{H}$-plane pattern at $2.5 \mathrm{GHz}$ shown in Figure 3(d) is due to the finite 


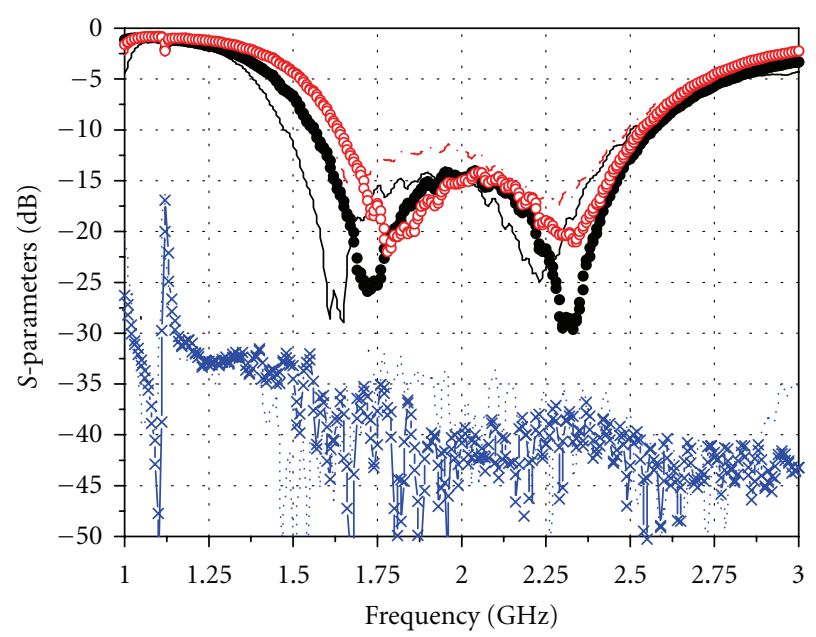

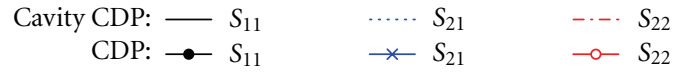

(a) Port return loss and isolation

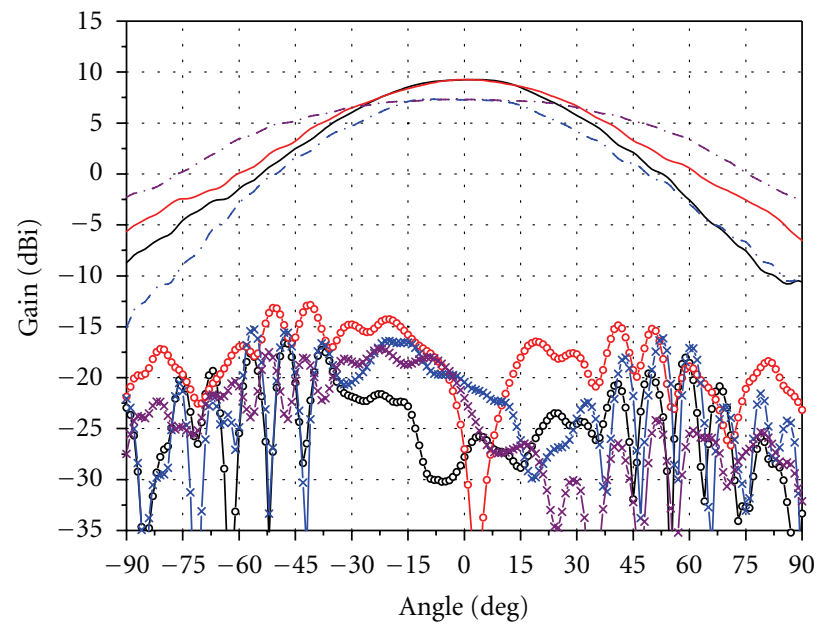

$f=2.1 \mathrm{GHz}$

Cavity CDP: — Co. at E-plane $\multimap$ Cx. at E-plane

Co. at H-plane $\multimap-\mathrm{Cx}$. at H-plane

CDP: -.- Co. at E-plane $\quad *$ Cx. at E-plane

-.- Co. at H-plane $\quad *$ Cx. at H-plane

(c) Radiation pattern at $2.1 \mathrm{GHz}$

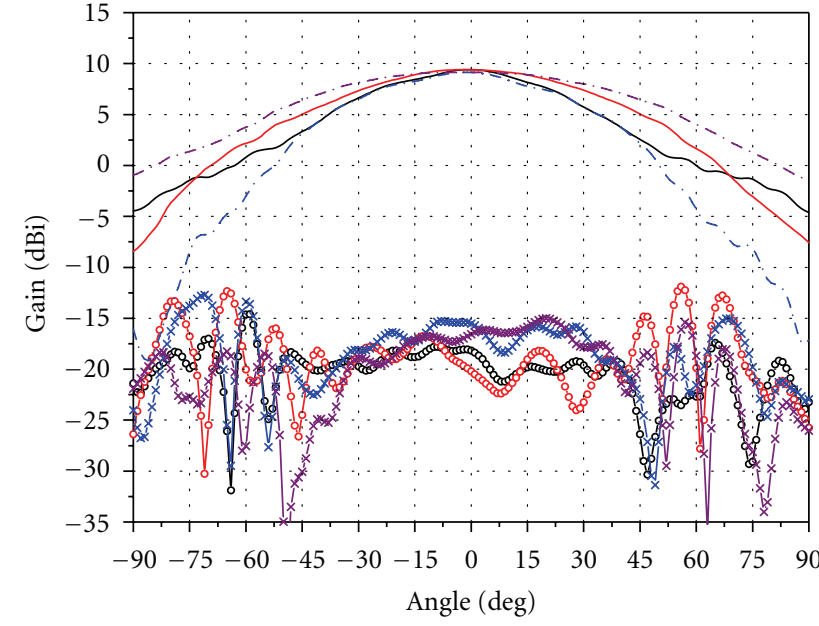

$f=1.7 \mathrm{GHz}$

Cavity CDP: — Co. at E-plane $\multimap$ Cx. at E-plane

- Co. at H-plane $-\circ$ Cx. at H-plane

CDP: -. Co. at E-plane $\quad \star$ Cx. at E-plane

-.- Co. at H-plane $\quad *$ Cx. at H-plane

(b) Radiation pattern at $1.7 \mathrm{GHz}$

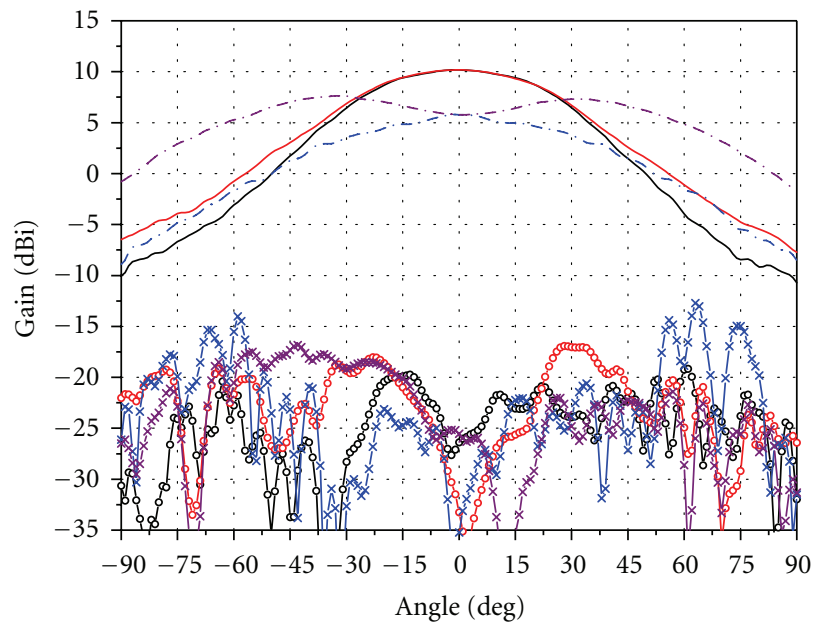

$f=2.5 \mathrm{GHz}$

Cavity CDP: — Co. at E-plane $\multimap-C x$. at E-plane

Co. at H-plane $\multimap$ Cx. at H-plane

CDP: -.- Co. at E-plane $\quad *$ Cx. at E-plane

-. Co. at H-plane $\quad *$ Cx. at H-plane

(d) Radiation pattern at $2.5 \mathrm{GHz}$

FIgURE 3: Measured electrical performances of the printed cross-dipole element with or without the cavity ring.

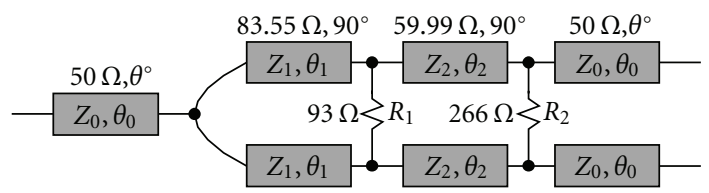

FIGURE 4: Two-stage Wilkinson power divider.

ground plane with the size of $200 \mathrm{~mm} \times 200 \mathrm{~mm}$ applied in the antenna prototype which corresponds to $2.35 \lambda_{o}$ at
2.5 GHz. The ground plane size and edges will have influence on the antenna properties, and the diffraction from the finite ground plane edges can cause main beam scalloping and can give a small effect on the directivity $[10,11]$. On the other hand, radiation patterns of the printed crossdipole element with the cavity ring show antenna gains at boresight of $9.4 \mathrm{dBi}, 9.2 \mathrm{dBi}, 10.2 \mathrm{dBi}$, respectively. The cross polarization performance is more than $21.2 \mathrm{~dB}$ within the $3 \mathrm{~dB}$ beamwidth and in the test frequencies irrespective of the usage of the cavity ring. 


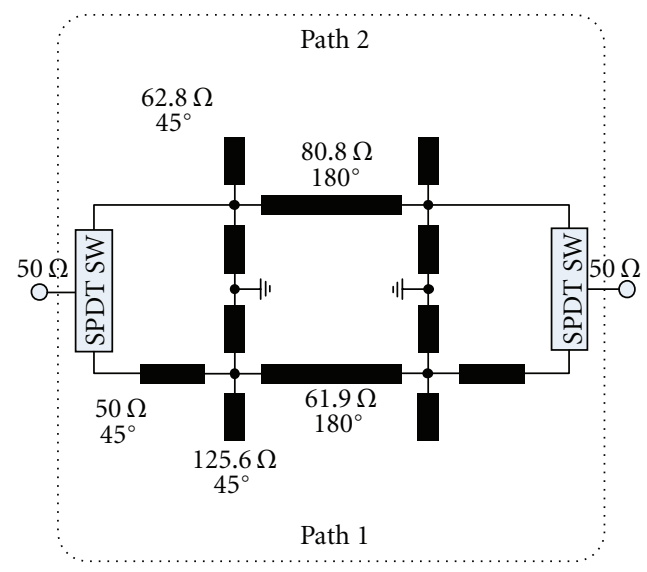

(a) $90^{\circ}$ BPS structure

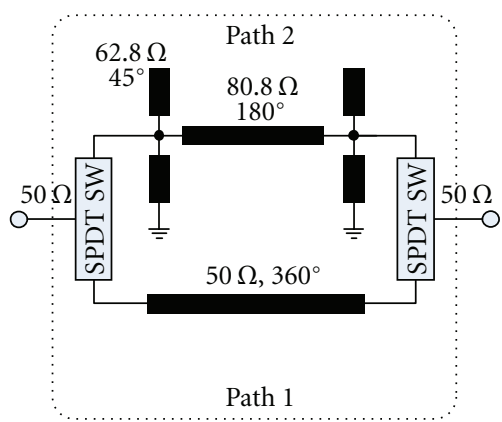

(b) $180^{\circ} \mathrm{BPS}$ structure

FIGURE 5: Broadband $90^{\circ} / 180^{\circ}$ phase shifter structures.

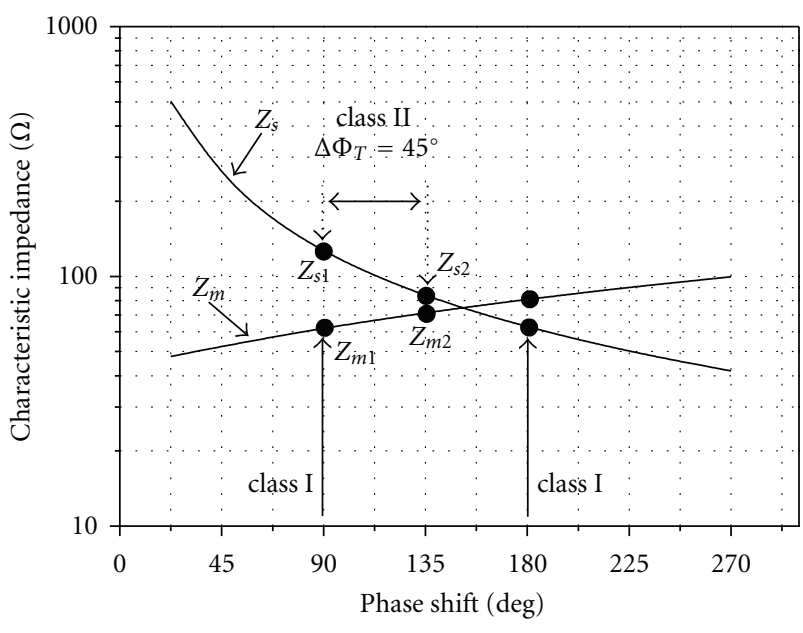

$Z_{0}=50 \Omega$

Figure 6: Design graph for $90^{\circ} / 180^{\circ}$ BPS [13].

These results reveal that the usage of the cavity ring provides radiation patterns of high quality and also a gain improvement of $1.9 \mathrm{~dB}$ and $4.4 \mathrm{~dB}$ at the middle and highest band, respectively.

2.2. Broadband Feed Network for Four Polarization Reconfigurations. As shown in Figure 1, the broadband feed network for four polarization reconfigurations (BFN_PR) is composed of a two-stage Wilkinson power divider with equal power ratio, a broadband phase shifter (BPS) of $90^{\circ}$-bit, a BPS of $180^{\circ}$-bit, and a digital polarization control circuit including a DC stabilizing circuit. The block diagram of the two-stage Wilkinson power divider is shown in Figure 4, and design values were obtained under the conditions of $f_{2} / f_{1}=1.5$, and $S_{11}(\max )=-35 \mathrm{~dB}, S_{22}, S_{33}(\max )=$ $-49 \mathrm{~dB}, I(\mathrm{~min})=37 \mathrm{~dB}[12]$, where $f_{1}$ and $f_{2}$ are the edge

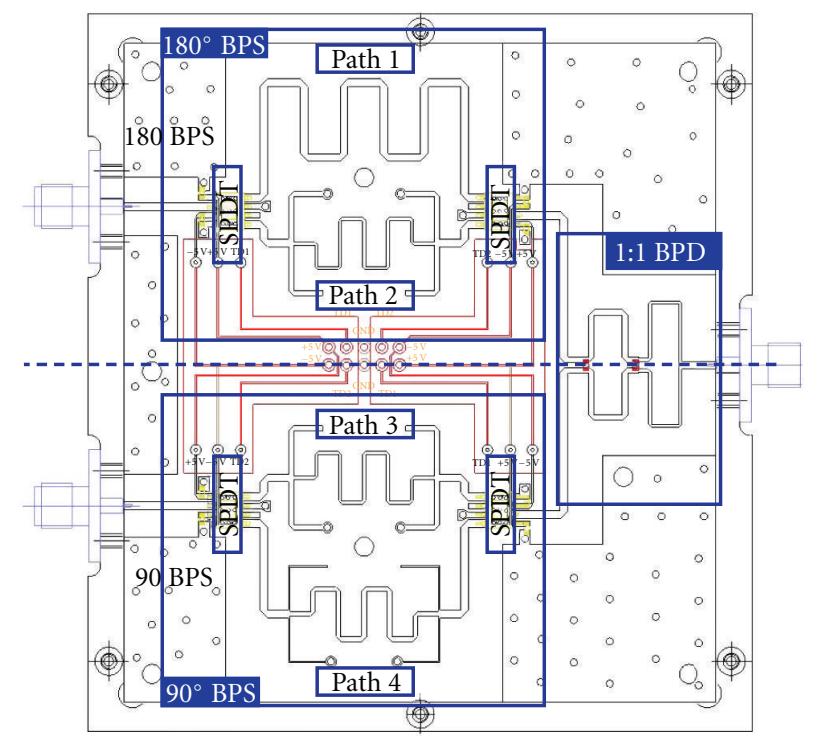

FIgURE 7: Fabricated BFN_PR prototype.

frequencies of the band $S_{11}, S_{22}$, and $S_{33}$ represent the return loss at each port, and $I$ represents the isolation between the output ports.

The block diagrams of broadband $90^{\circ} / 180^{\circ}$ phase shifters are shown in Figure 5. The phase shifters used in this paper were switched network types that were detailed in [13]. The $90^{\circ}$ BPS structure of Figure 5(a) can achieve over octave bandwidths, and the $180^{\circ}$ BPS structure of Figure 5(b) can operate in approximately a 50\% fractional bandwidth. Each network is composed of two paths, Path 1 and Path 2, and a path is chosen by the simultaneous operation of two SPDT (Single Pole Double Throw) switches. SWM-250DR switches of mini-circuits are utilized in this design. Its insertion loss is about $1.5 \mathrm{~dB}$, and the in-out isolation is more than $35 \mathrm{~dB}$ in the operating band. Path 2 has a more dispersive phase property than Path 1 , and the phase 

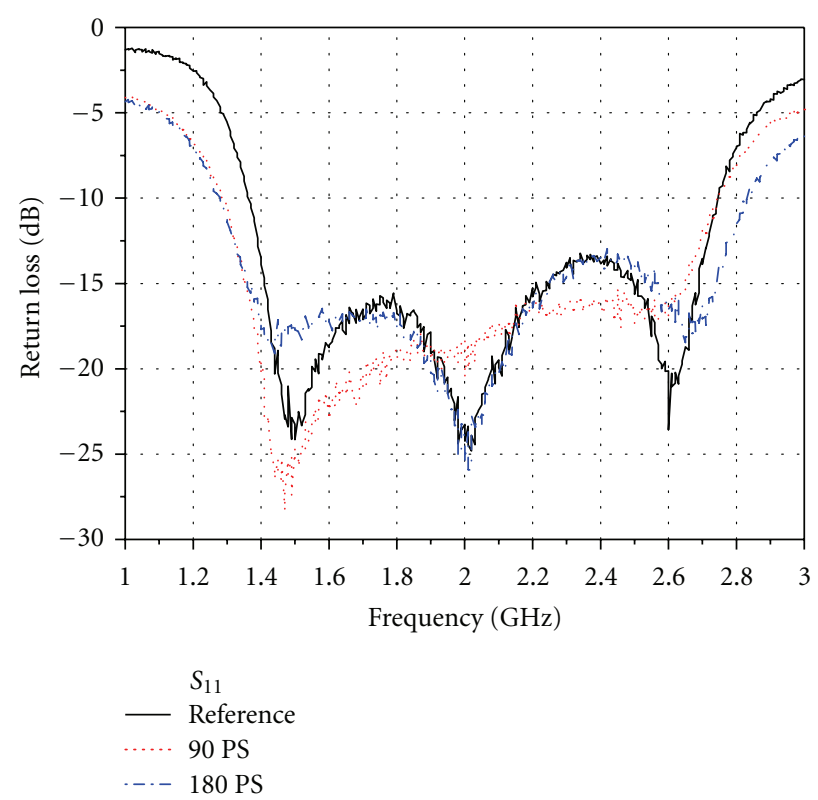

(a) $S_{11}$
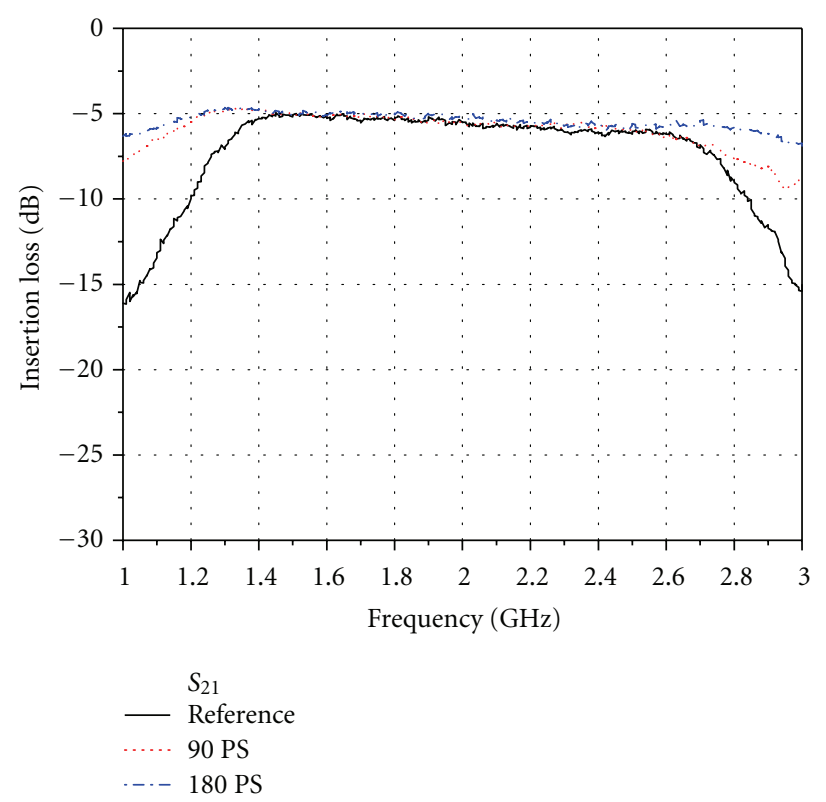

(c) $S_{21}$

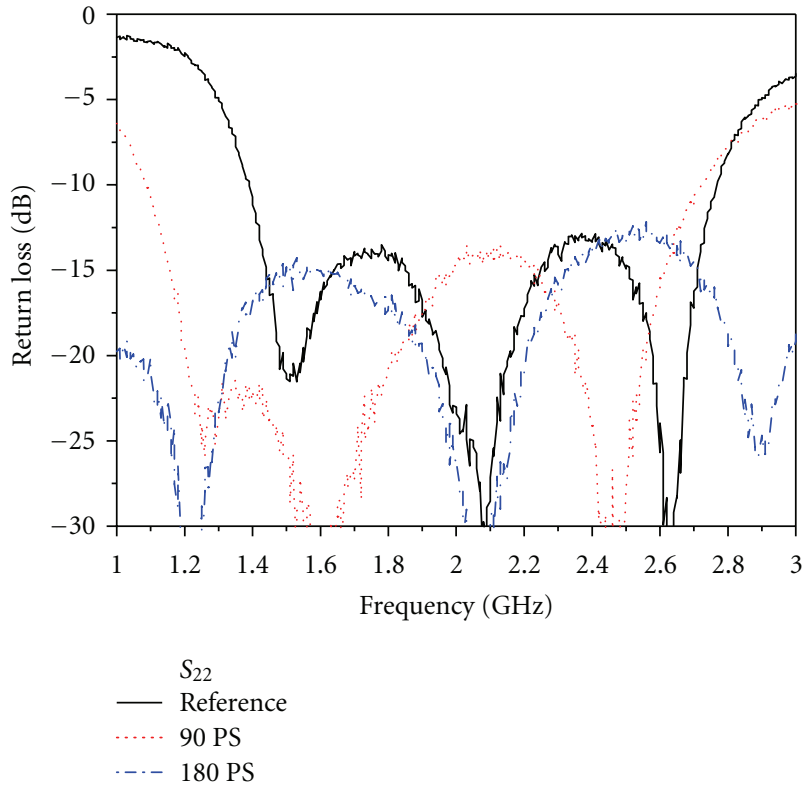

(b) $S_{22}$
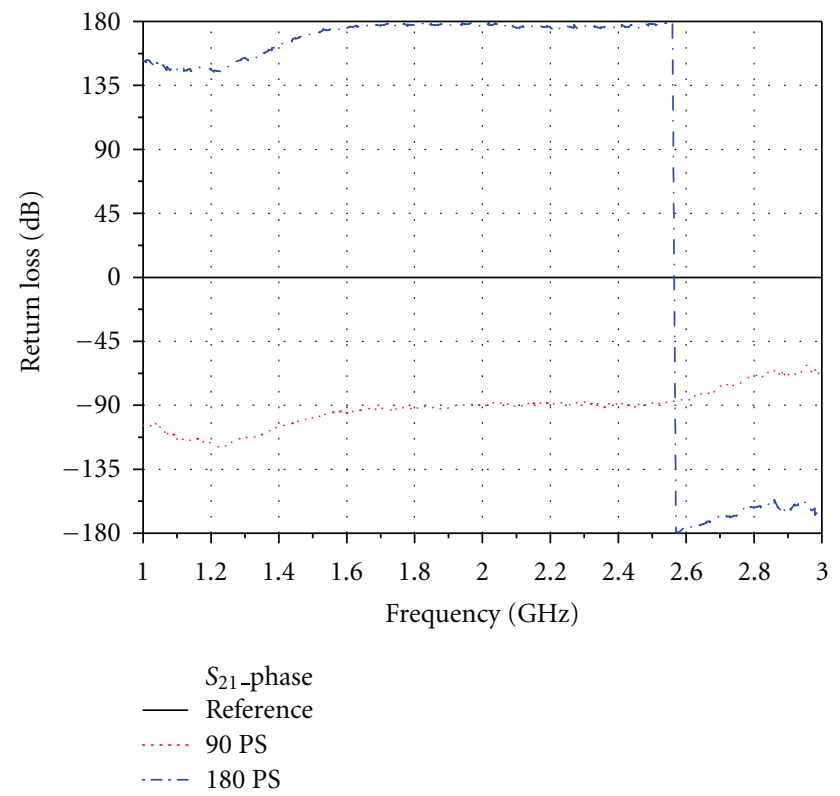

(d) phase of $S_{21}$

FIGURE 8: Measured electrical performances of the BFN_PR prototype.

slope can be controlled by the specific values of $Z_{m}$ to $Z_{s}$. The design parameters of broadband $90^{\circ} / 180^{\circ}$ phase shifter structures are determined by the design graph of Figure 6.

The internal PCB and component layout of the prototype fabricated to verify the electrical performances of the BFN_PR is shown in Figure 7. The BFN_PR circuit was also realized on an RF35 board from the Taconic company with a dielectric permittivity of 3.5 and a thickness of $0.508 \mathrm{~mm}$, and a conductor thickness of $0.035 \mathrm{~mm}$. Electrical design parameters of the BFN_PR are given in Figures 4 and 5.
Figure 8 shows the measured electrical performances of the BFN_PR. The measured input and output return losses are less than $-13.0 \mathrm{~dB}$ and $-12.5 \mathrm{~dB}$, respectively, in the operating band, and the measured insertion loss is less than $-6.3 \mathrm{~dB}$ in the operating band. If the insertion losses of the two SPST switches assembled on each path of a switched network are excluded, the practical loss by the physical length and impedance mismatch is just about $-3.3 \mathrm{~dB}$. This means the BFN_PR itself has a very low loss or high efficiency. In addition, the relative phase shift error to the required 


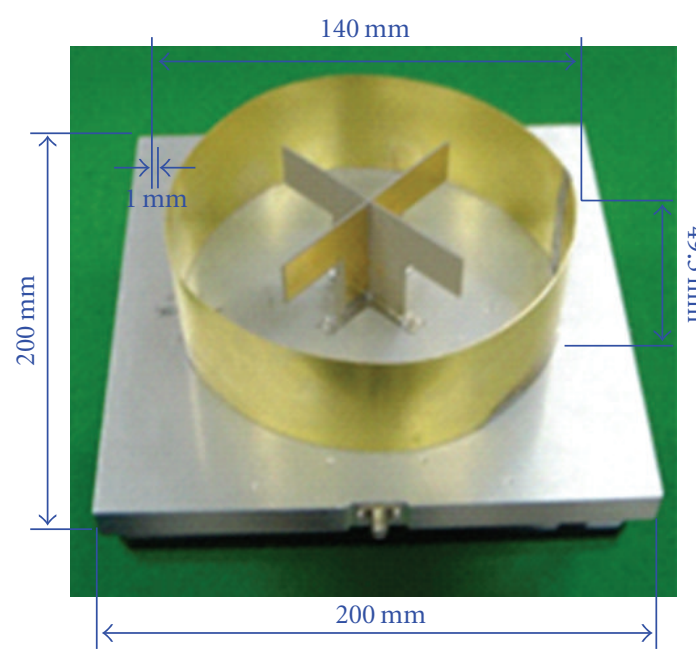

(a) Front side

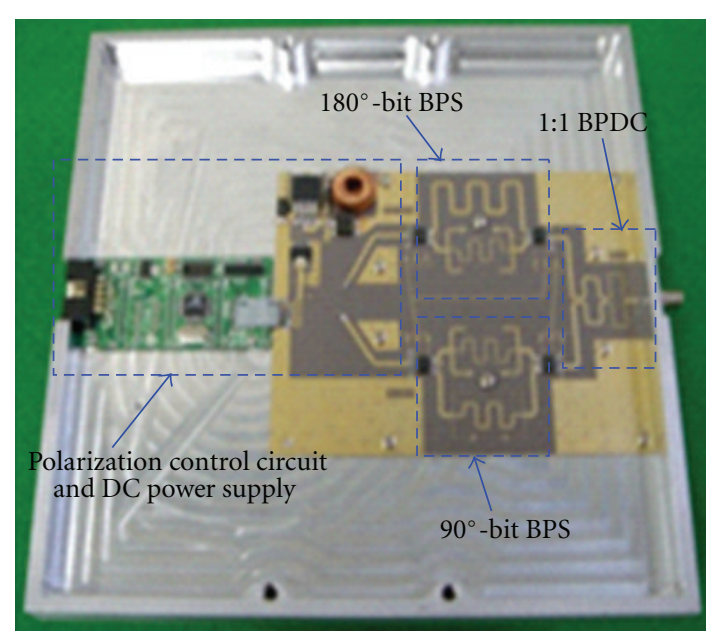

(b) Back side

FIgure 9: Photos of the fabricated BPCDE_PR prototype.

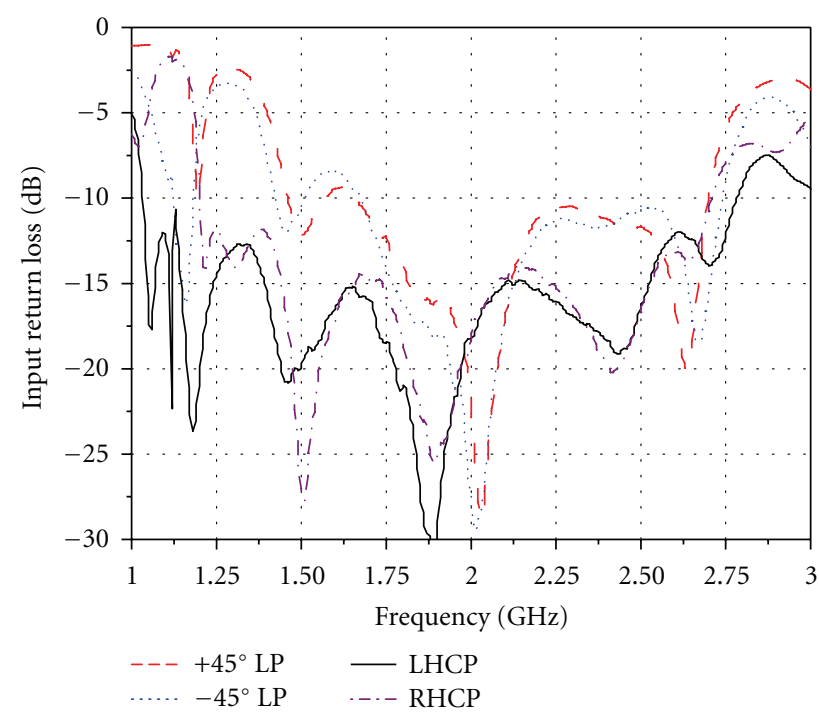

FIGURE 10: Measured return loss of the BPCDE_PR prototype versus polarization reconfigurations.

phase shift is less than $\pm 3.6^{\circ}$ and $+5.5^{\circ}$ at $90^{\circ}$ and $180^{\circ}$ bit, respectively, in the operating band.

\section{Experimental Results}

The BPCDE_PR prototype fabricated for testing four polarization reconfigurations is shown in Figure 9. The printed cross-dipole element was assembled on a base plate of $150 \mathrm{~mm} \times 150 \mathrm{~mm}$ to reflect the electromagnetic wave radiated from it to the boresight direction. Two outputs of the BFN_PR were connected with the cross-dipole element through two short coaxial lines with the same electrical length.

Polarization reconfigurations of the BPCDE_PR can be obtained by the digital polarization control circuit which makes relative phase differences of $0^{\circ}, 180^{\circ}, 90^{\circ}$, and $-90^{\circ}$, respectively, at two outputs of the BFN_PR. The control paths for polarization reconfigurations in Figure 7 are given in Table 1. Path 2 and Path 3 are the reference paths at each switched network.

The input return losses measured according to the polarization reconfigurations are shown in Figure 10, and the performances are less than $-10.5 \mathrm{~dB}$ for four different polarizations in the operating band.

The radiation patterns and axial ratios measured according to the polarization reconfigurations are shown in Figures 11 and 12, respectively. The gain and axial ratio performances of the BCDE_PR by test frequencies and different polarizations are summarized in Table 2.

Table 2 shows that the measured gain of the BPCDE_PR is the range of $6.66-7.47 \mathrm{dBi}$ (with a $0.81 \mathrm{~dB}$ gain difference). 


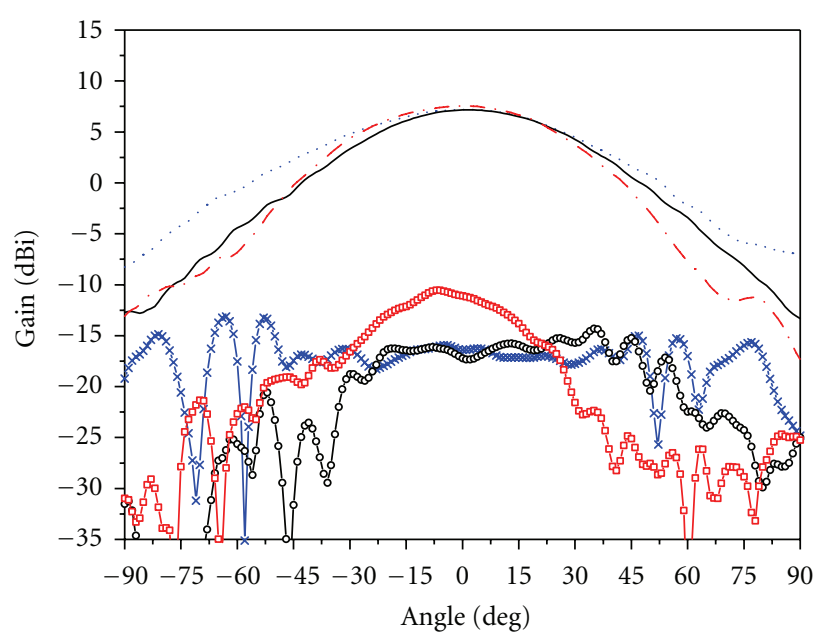

$+45^{\circ}$ Linear Pol.

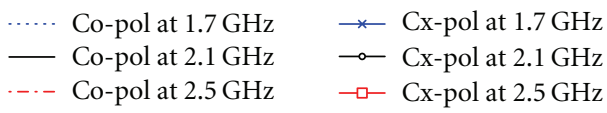

(a) $+45^{\circ}$ linear pol.

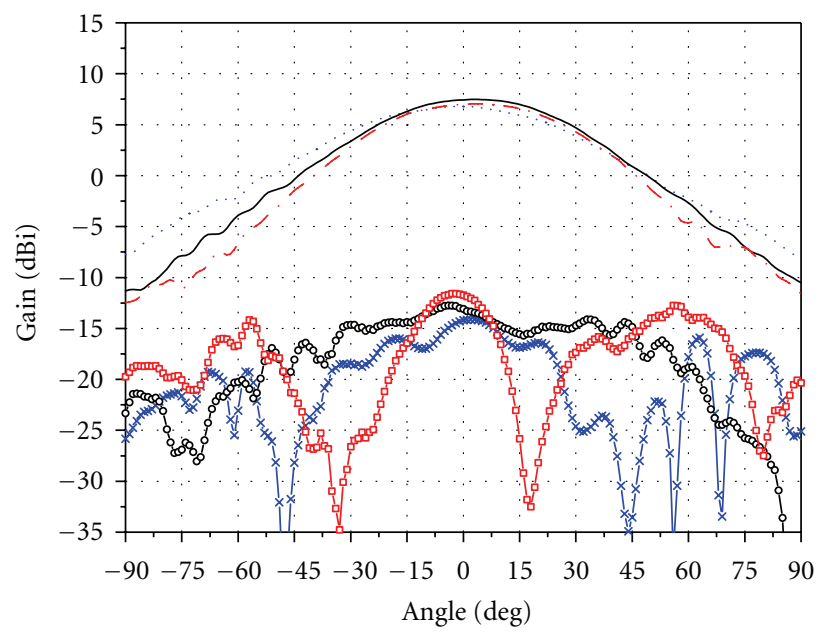

LHCP

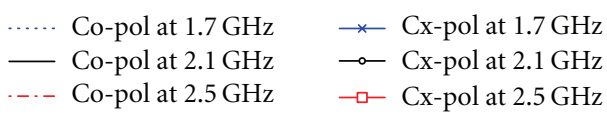

(c) LHCP

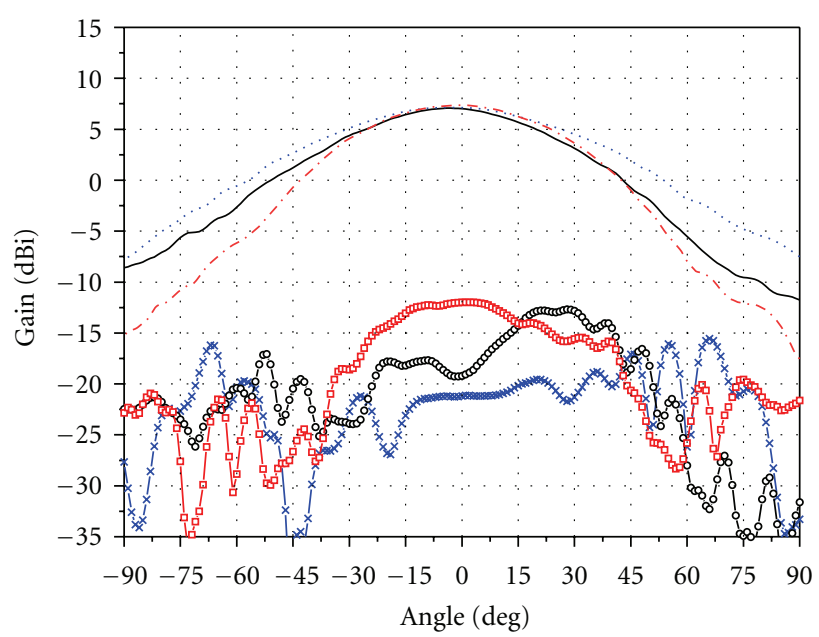

$-45^{\circ}$ Linear Pol.

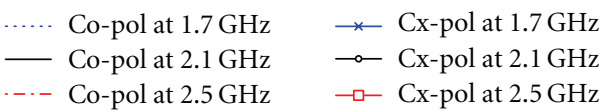

(b) $-45^{\circ}$ linear pol.

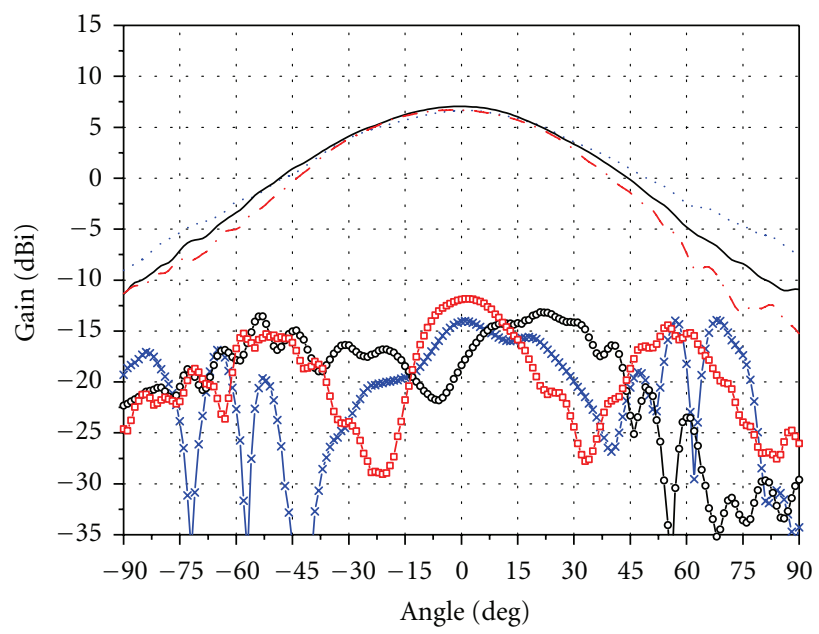

RHCP

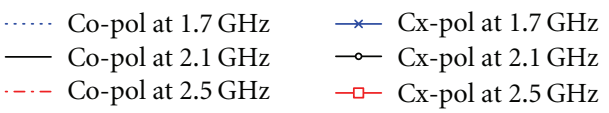

(d) RHCP

Figure 11: Measured radiation patterns of the BPCDE_PR prototype.

The measured antenna gains are lower than the antenna gains of Figures 3(b)-3(d) due to the insertion loss of two SPST switches used in the feed network as shown in Figure 8(c). If SPDT switches with low loss are used or active amplifiers with low noise or high power between the printed crossdipole elements and the polarization control circuit are used, the antenna gains would be increased and antenna efficiencies would be also increased.

The measured axial ratios of $+45^{\circ}$ and $-45^{\circ}$ linear polarizations within $3 \mathrm{~dB}$ beamwidth are less than $-17.89 \mathrm{~dB}$ and
$-17.02 \mathrm{~dB}$ in the operating band, respectively. The axial ratios of the LHCP and RHCP are less than $2.08 \mathrm{~dB}$ and $2.23 \mathrm{~dB}$, respectively. The axial ratio performances could be improved a little in the next design by fine-matching the BFN_PR with the broadband printed cross-dipole element.

The measured gain performances versus the frequency of the BPCDE_PR prototype are shown in Figure 13. The frequency gain responses of $+45^{\circ}$ and $-45^{\circ}$ linear polarizations are within the range of $6.75-8.48 \mathrm{dBi}$ and $6.50-8.93 \mathrm{dBi}$ for the operating band, respectively, and also the frequency 

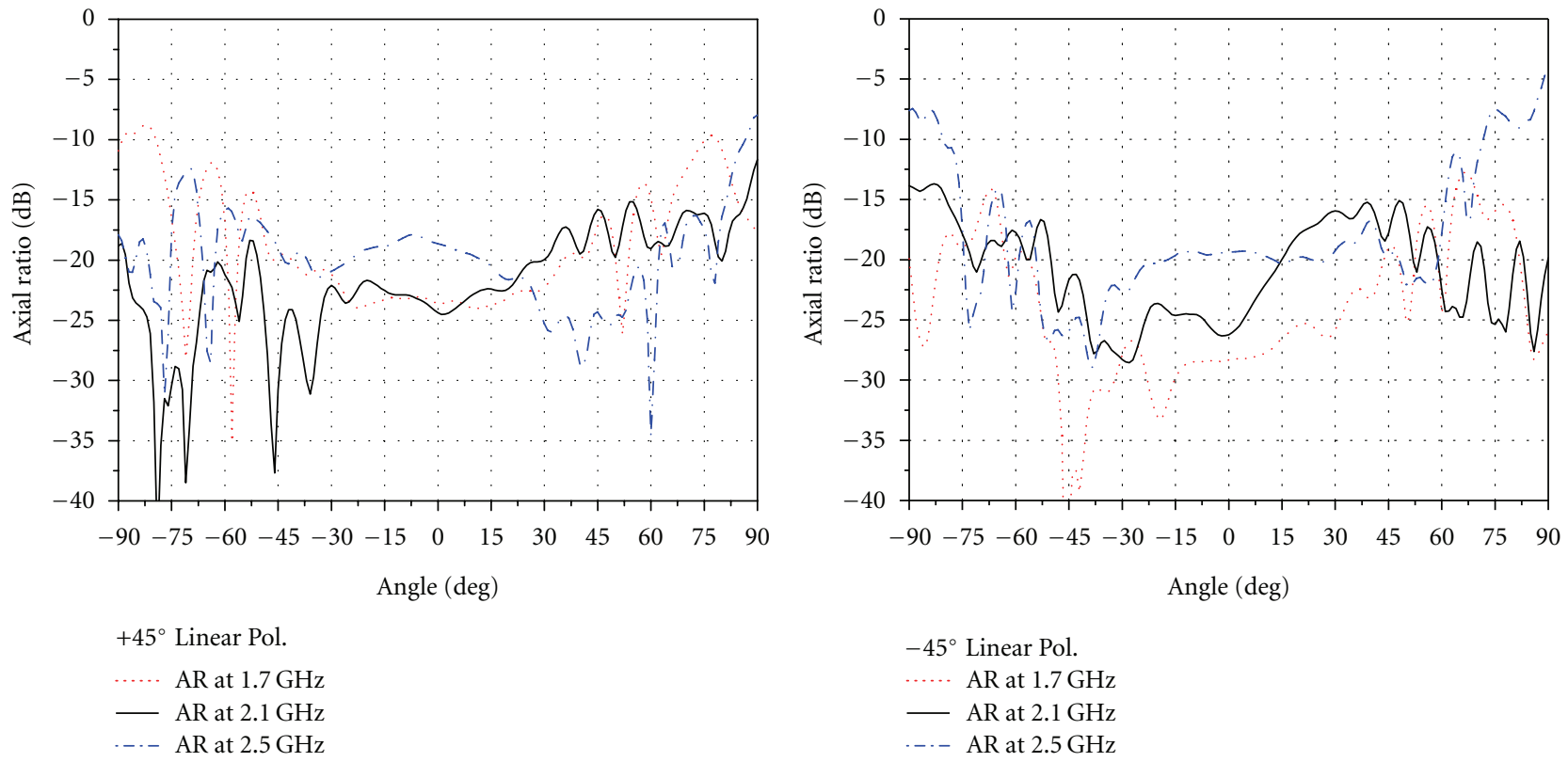

(a) $+45^{\circ}$ linear pol.

(b) $-45^{\circ}$ linear pol.

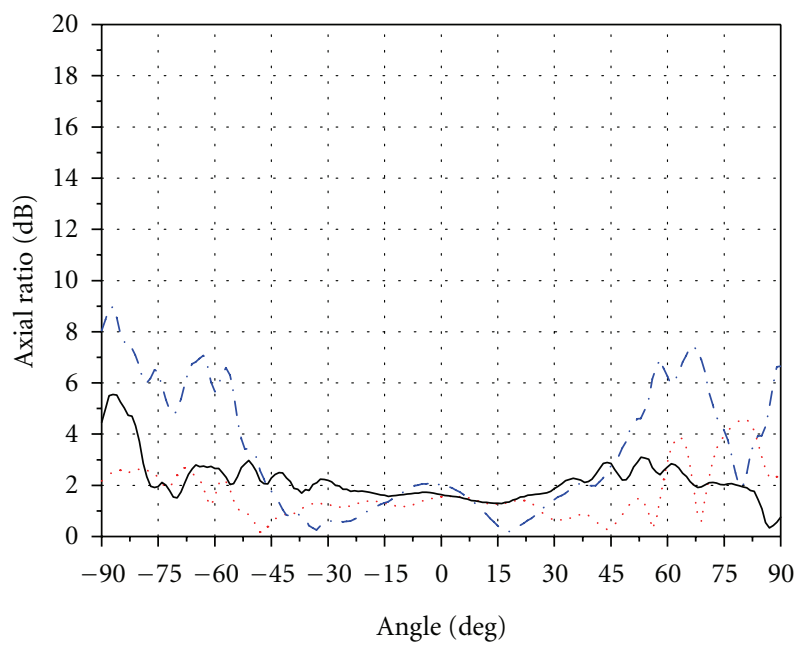

LHCP

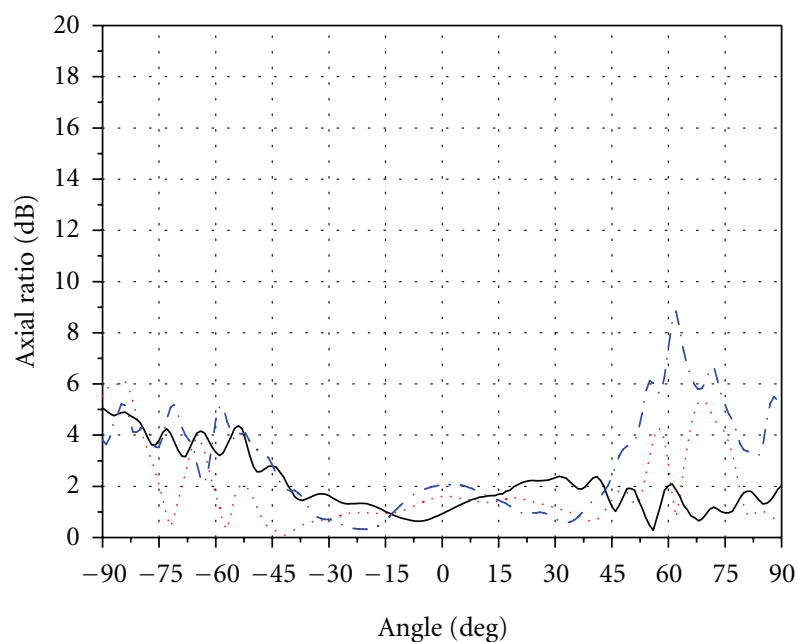

…. AR at $1.7 \mathrm{GHz}$

RHCP

— AR at $2.1 \mathrm{GHz}$

… AR at $1.7 \mathrm{GHz}$

- $\mathrm{AR}$ at $2.1 \mathrm{GHz}$

...- AR at $2.5 \mathrm{GHz}$

... $\mathrm{AR}$ at $2.5 \mathrm{GHz}$

(c) LHCP

(d) RHCP

FIGURE 12: Measured axial ratios of the BPCDE_PR prototype.

gain responses of the LHCP and RHCP are within the range of $6.35-9.08 \mathrm{dBi}$ and $6.16-8.99 \mathrm{dBi}$, respectively. The cross polarization performances at the bore sight are more than $19.86 \mathrm{~dB}, 18.29 \mathrm{~dB}$ and $18.64 \mathrm{~dB}, 17.89 \mathrm{~dB}$, respectively, for the operating band.

\section{Conclusions}

A broadband printed cross-dipole element and feed network were designed and fabricated to test four polarization re- configurations composed of two linear and two circular polarizations in the operating band of $1.7-2.5 \mathrm{GHz}$. To implement the broadband polarization reconfigurations, broadband $90^{\circ} / 180^{\circ}$ phase shifters of switched network types were designed and showed good electrical performances. The fabricated BPCDE_PR showed appropriate polarization reconfigurations and good electrical performances in the operating band of about $40 \%$. The proposed antenna in this paper can be used as an array element in broadband base stations and repeater antennas or as a broadband 


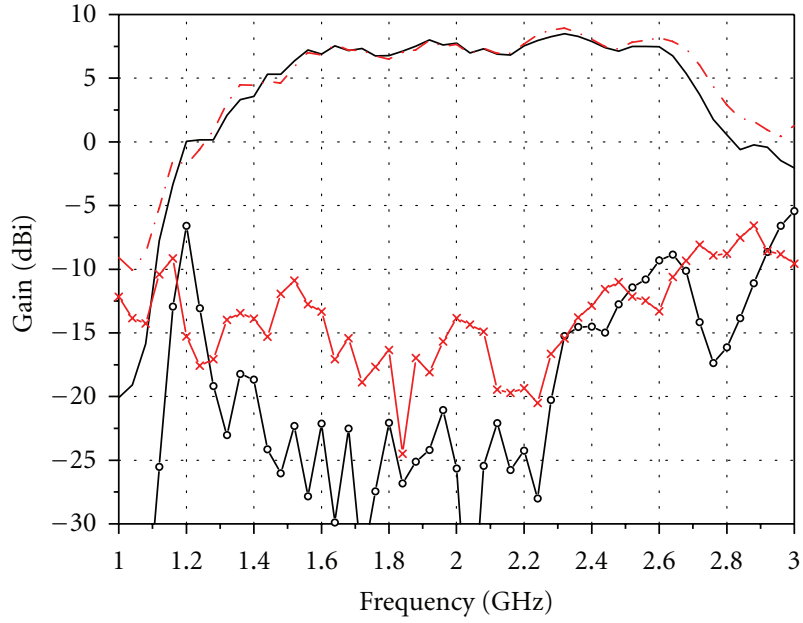

Gain versus Freq @ LP

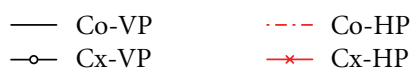

(a) Linear

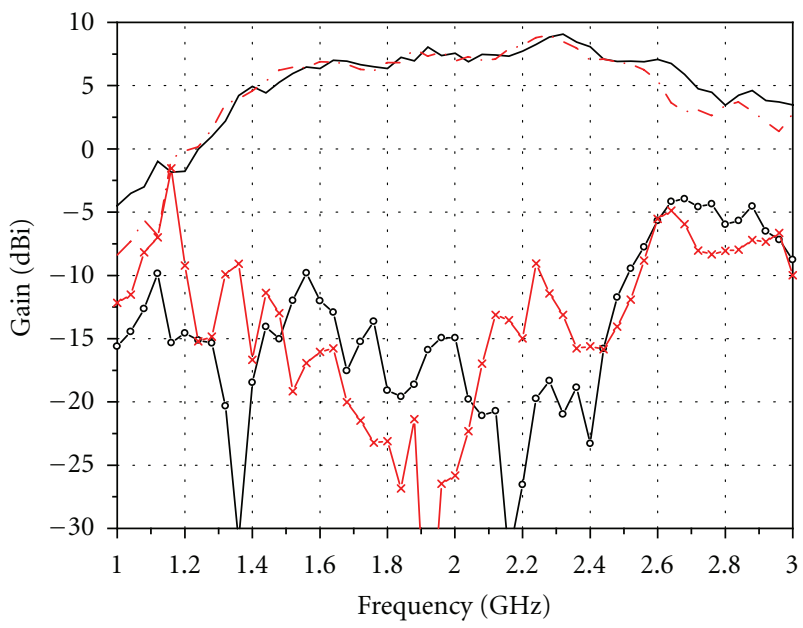

Gain versus Freq @ CP

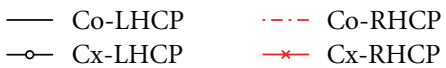

(b) Circular

FiguRE 13: Measured gain performances versus frequency of the BPCDE_PR prototype.

terminal antenna because of its broadband characteristics and polarization reconfigurability.

\section{References}

[1] Y. J. Sung, T. U. Jang, and Y. S. Kim, "A reconfigurable microstrip antenna for switchable polarization," IEEE Microwave and Wireless Components Letters, vol. 14, pp. 534536, 2004.

[2] K. Chung, Y. Nam, T. Yun, and J. Choi, "Reconfigurable microstrip patch antenna with switchable polarization," ETRI Journal, vol. 28, no. 3, pp. 379-382, 2006.

[3] M. K. Fries, M. Gräni, and R. Vahldieck, "A Reconfigurable Slot Antenna with Switchable Polarization," IEEE Microwave and Wireless Components Letters, vol. 13, no. 11, pp. 490-492, 2003.

[4] L. N. Pringle, P. H. Harms, S. P. Blalock et al., "A reconfigurable aperture antenna based on switched links between electrically small metallic patches," IEEE Transactions on Antennas and Propagation, vol. 52, no. 6, pp. 1434-1445, 2004.

[5] B. A. Cetiner, H. Jafarkhani, J. Y. Qian, H. J. Yoo, A. Grau, and F. De Flaviis, "Multifunctional reconfigurable MEMS integrated antennas for adaptive MIMO systems," IEEE Communications Magazine, vol. 42, no. 12, pp. 62-70, 2004.

[6] S. Xiao, B. Z. Wang, and X. S. Yang, "Novel Frequency Reconfigurable Patch Antennas," Microwave and Optical Technology Letters, vol. 36, pp. 295-297, 2003.

[7] C. A. Balanis, Antenna Theory Analysis and Design, chapter 2, 2nd edition, 2010.

[8] H. R. Chuang and L. C. Kuo, "3-D FDTD design analysis of a $2.4-\mathrm{GHz}$ polarization-diversity printed dipole antenna with integrated balun and polarization-switching circuit for WLAN and wireless communication applications," IEEE Transactions on Microwave Theory and Techniques, vol. 51, no. 2 I, pp. 374381, 2003.

[9] N. C. Karmakar, "Investigations into a cavity-backed circularpatch antenna," IEEE Transactions on Antennas and Propagation, vol. 50, no. 12, pp. 1706-1715, 2002.

[10] J. Huang, "The finite ground plane effect on the microstrip antenna radiation pattern," IEEE Transactions on Antennas and Propagation, vol. 31, no. 4, pp. 649-653, 1983.

[11] S. A. Bokhari, J. R. Mosig, and F. E. Gardiol, "Radiation pattern computation of microstrip antennas on finite size ground planes," IEE Proceedings Hs, vol. 139, no. 3, pp. 278-286, 1992.

[12] S. B. Chon, "A class of broadband three-port TEM-mode hybrids," IEEE Transactions on Microwave Theory and Techniques, vol. MTT-16, no. 2, pp. 110-116, 1968.

[13] S. Y. Eom and H. K. Park, "New switched network phase shifter with broadband characteristic," Microwave and Optical Technology Letters, vol. 38, no. 4, 2003. 

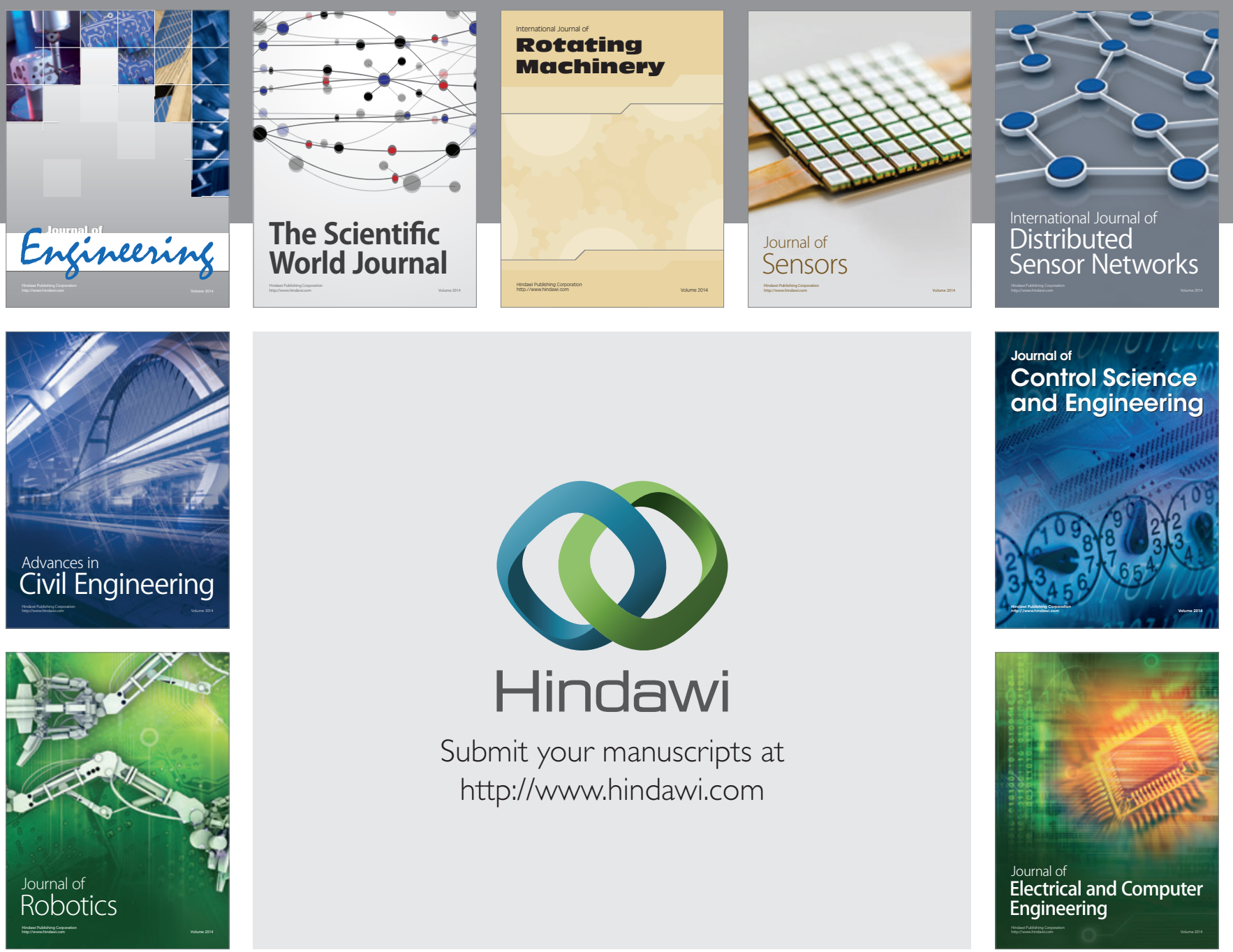

Submit your manuscripts at

http://www.hindawi.com
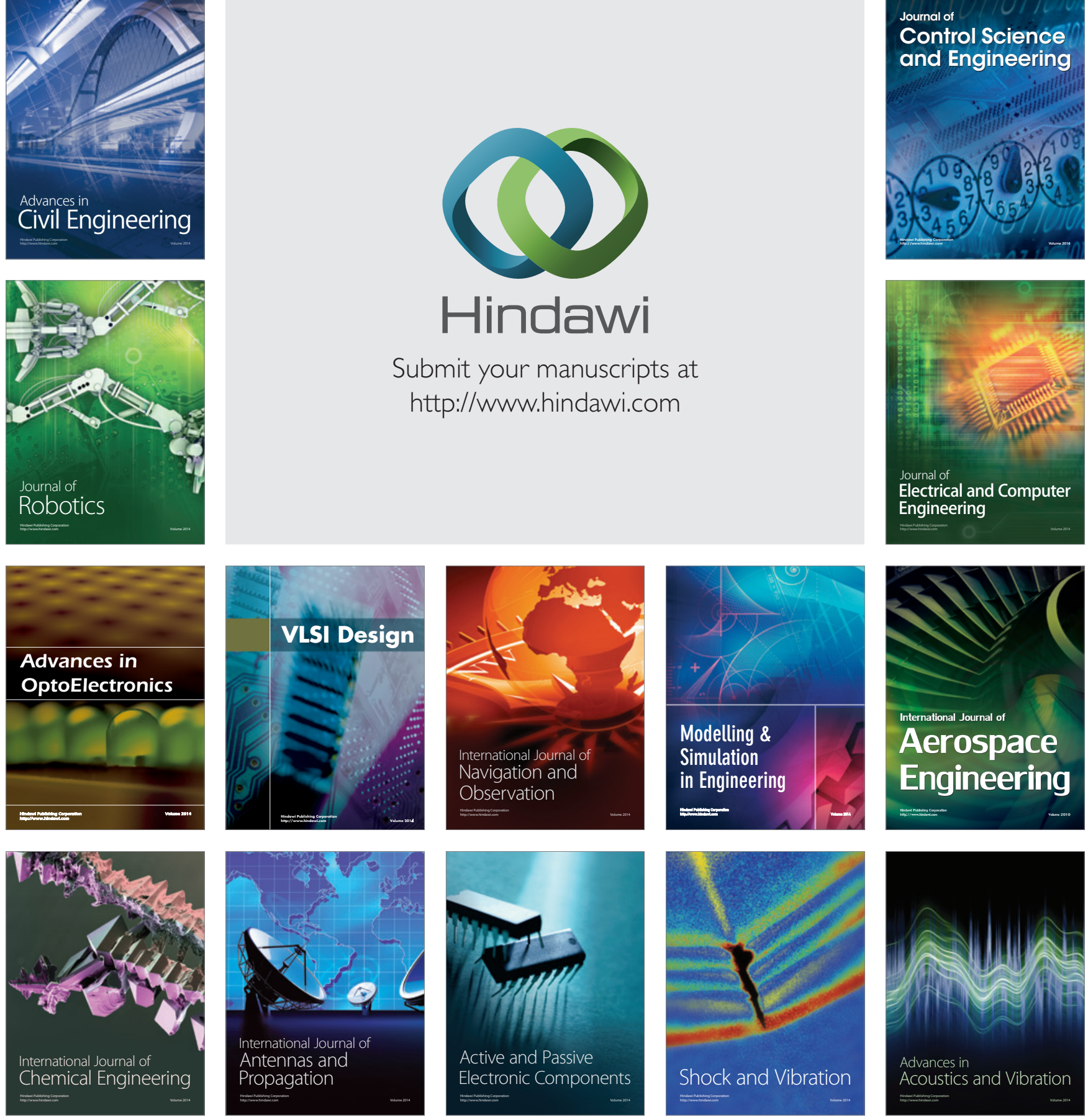